\title{
FOREIGN LANGUAGE TEACHING METHOD
}

\section{AKMARAL A. BATAYEVA}

Master of humanitarian science department of chinese philology,

L. N. GUMILYOV Eurasian national university, Nur-Sultan Kazakhstan

e-mail malali2012@mail.ru

\section{AKHMETBEK GULZHAN}

$\mathrm{PhD}$, associate professor of 1.n.gumilyov Eurasian national university,

Nur-Sultan Kazakhstan,

e-mail: akhmetbek.gulzhan@gmail.com

\section{KARAKAT TOIBOL,}

Master of international chinese language teaching,

L. N. GUMILYOV Eurasian national university,

Nur-Sultan Kazakhstan

e-mail: karakat85@mail.ru

\section{TURSYN PAZILAT}

Teacher,

Kazkh Ablai Khan university of international relations and world languages faculty of oriental studies,

Graduated from the magistracy master of teaching chinese to speakers of other languages,

e-mail: Pazilat.tursyn@mail.ru

\section{AKMATOVA ANARA SYDYKOVNA,}

Teacher of Bishkek state university kyrgyz-chinese faculty,

Bishkek, Kyrgyzstan,

e-mail: anakmatova@gmail.com

\begin{abstract}
:
There are various teaching methods when teaching a foreign language, it is necessary to pay attention to new ways to stimulate the speech of students. However, numerous classical schools still try to teach by the old methods and from the old books. There will always be problems, and you will never speak the foreign language well. By using new methods, it is easy to learn to speak English and improve at it. You will be able to speak like a native speaker.
\end{abstract}

KEYWORDS: Methodology, English, teaching, foreign languages, translation method.

Article Received: 18 October 2020, Revised: 3 November 2020, Accepted: 24 December 2020

In the methodology of teaching foreign languages, the method is considered to be the way to achieve the set goal, however, it is used to denote paths of different scale. The method is called the fundamental direction in teaching foreign languages, characterized by certain goals, content and principles of teaching (grammar-translation method, direct method, etc.). So, with the grammar-translation method, training was conducted with the aim of developing logical thinking and the ability to read and translate texts. The main attention was paid to the study of grammar rules as a necessary tool in mastering a foreign language, and above all reading. When teaching by the direct method, the main goal was the development of practical skills to use a foreign language: understand it, speak it, as well as read and write. The word method denotes a pathsystem of teaching within a direction, reflecting the concept of the author (s) who proposed it (Francois Guin's method, Palmer's method within a direct method-direction).

The word method indicates the way - the way of the ordered interrelated activity of the teacher and students within any system, to a technological operation that ensures the interaction of the 
teaching and learning parties and is included as a component in the teaching technology directly related to the problem of how to teach, based on that the organization and implementation of the pedagogical process occurs: by means of teaching methods, implemented in methodological techniques; using a variety of learning tools; when using various organizational forms of students' work; taking into account the age of students, the level of their training in a foreign language and general development, the degree of training, educational material and the time allotted for its study.

The methodology of teaching foreign languages is a system of knowledge about the laws of the process of teaching a foreign language and the ways of influencing this process in order to optimize it. The method of teaching a foreign language (FL) reveals and substantiates the patterns of teaching a foreign language. Historically, two functionally different methods have developed: general and specific methods. The general methodology, as a rule, is devoted to the study of the patterns and characteristics of the process of teaching a foreign language, regardless of what foreign language is in question. So, the principles of the selection of educational material, the ratio of oral and written speech at various stages of the lesson, etc. in equivalent learning conditions will be the same for any of the Western European languages studied in the general education schools of our country. However, knowledge of the general laws of learning FL turns out to be insufficient when the teacher is faced with the specific features of a particular foreign language. Thus, the methods of mastering the verbal forms of Continuous are specific only for the English language, cumbersome models of composition, the declension of nouns and adjectives are typical for the German language, and the methods of forming numbers, the use of diacritics, the abbreviation of the article, the presence of the partitive article are in French.
Significant differences are observed in phonetics: triphthongs and diphthongs are specific for English, nasal vowels are specific for French. As experience and practice show, the teacher needs to develop and implement such techniques, methods and forms of teaching, which contributed to the rapid mastery by students of the corresponding specific phenomena in a particular foreign language. Thus, a private methodology explores the teaching of those linguistic and speech phenomena that are specific to a particular foreign language being studied. General and specific methods are interconnected. The general methodology is enriched based on the experience of private methods. In turn, the regularities of the general methodology are reflected in the private one. The subject of the methodology of teaching foreign languages is the accumulated knowledge about the object, a numerous theory that simulates the learning process; these are the regularities of the learning process of FL. The basic concepts that make up the foundation of the methodology include: process, goals, content, principles, methods, techniques, means and organizational forms of training. The basic categories of the methodology are considered to be: Method as a system of purposeful actions of the teacher, on the one hand, and educational actions of students, on the other. Reception - an elementary methodical act aimed at solving specific problems at a certain stage of the lesson. The method is implemented in a system of techniques. The communicationoriented teaching method is implemented in the following techniques:

- Reception of role-based communication

- Reception of the formation of the approximate ability of students

Techniques for teaching speech interaction

- Techniques for systematizing speech knowledge

- Techniques for deepening and expanding content

- Increasing the intensity of independent work 
- Techniques for stimulating speech-thinking activity by means of TCO.

- Techniques for standardized control.

The approach is a common starting position, starting from which the researcher considers most of his other positions. The question of the relationship between method and approach remains controversial. Domestic methodologists and most foreign researchers believe that the approach to teaching plays a fundamental role and is the dominant idea on which the new method is built. The method and approach are interrelated and interdependent, they are characterized by constant interaction. Researchers unanimously express the opinion that there is no absolutely correct and effective method for all learning conditions and come to the conclusion that it is necessary to combine different approaches, principles and elements of different methods, taking into account the specifics of learning, since what is effective in one setting can have a completely opposite result in different learning conditions. The principle is the guiding idea. It is customary to single out the following general didactic, general methodological, private methodological principles. K.V. MinyarBeloruchev in his research distinguishes the following principles of teaching: the principle of a differentiated approach, the principle of managing the learning process, the principle of isolating specific reference points, the principle of an integrated approach to motivation in teaching a foreign language.

The goal of learning is what we strive for in the process of learning IL, it is an ideally planned result. First, the goal of training is set, only then a methodology is developed. The goal of training is closely related to the conditions of training, since without them its achievement is impossible. Learning conditions are the circumstances under which learning takes place. The means of teaching are the tools of the educational process, with the help of which the set goals are more successfully and in a short time achieved. The teaching aids include: textbook, workbook, tape recorder, cards. All of the above categories serve the educational system, a general model of the educational process, corresponding to a certain methodological concept. The training system is a complete set of components corresponding to a specific methodological concept; it determines the goals, content, principles, methods, techniques, methods, means, forms of organization of training and, in turn, is conditioned by them. The system of teaching a foreign language is based on the provisions on the universal connection and interdependence of the phenomena of reality, on the integrity of the continuously developing world and the systematic reflection of our knowledge about it. The integrity of the system is ensured by the multiple connections between its elements and their interaction during the functioning of the system. With regard to teaching foreign languages, it is advisable to consider the concept of a system at two levels: at the level of the most significant phenomena and processes that determine the initial provisions of the methodology of teaching foreign languages; at the level of the pedagogical process, that is, the activities of the teacher and students, mediated by the educational complex, which determines the final result - a certain degree of training.

The methodology of teaching foreign languages is associated with a number of other sciences - basic and related. The basic sciences include philosophy, pedagogy, psychology, psycholinguistics, linguistics, communication theory, etc. The data from related sciences are used by the methodology as a means of ensuring the effectiveness and reliability of their research. The link with linguistics is important and necessary for the methodology.

The subject of training is the teaching of speech activity on the material of the language. Linguistics, on the other hand, describes the main system properties of a particular language, 
formulates them in rules that are actively used by the methodology in the development of specific training models. The technique is closely related to psychology. The methodology uses the data of psychological science on the peculiarities of perception in teaching a foreign language, the role of thinking and its connection with language, the relationship between the conscious and the unconscious (a combination of voluntary and involuntary attention, awareness and imitation), the formation of skills and abilities, the motivation of educational activity, etc. provisions of the methodology is based on the research of L.S. Vygotsky, S.L. Rubinstein, A.N. Leont'ev, in which the theory of activity, in particular mental activity, is being developed, draws on data on memory problems, the formation of speech skills, speech mechanisms, takes into account the theory of installation, etc. A great contribution to the development of the methodology was made by scientists who devoted their works to the development of issues of teaching a foreign language. The merit of V.A. Artemova, B.A. Belyaev and other psychologists is that they not only approved speech as an object of training, but also provided a psychological justification for the need to teach speech in all forms in a foreign language. Based on general psychology, educational psychology, psychology of teaching a foreign language, the methodology draws from them data on the psychological characteristics of speech, on speech, oral and written, external and internal.

It is undeniable that using the general psychological concepts of the formation of skills and abilities in activity, the methodology refines them on the basis of its own subject and enriches the general psychological theory of activity with such specific categories as speech skill, speech ability. Consequently, the connection between the methodology and psychology should be understood not as an elementary use of psychological theory by the methodology, but as a bilateral dialectical relationship that contributes to the mutual clarification, supplement and enrichment of the theories of both sciences. Connections with psycholinguistics, which have developed at the intersection of psychology and linguistics and which study the mechanisms of speech generation (expression of thoughts) and speech recognition (speech understanding), are important for the methodology. Knowledge of the mechanisms for the implementation of speech activity is of particular importance for the correct construction of the educational process, because teaching a language is teaching speech activity. The contribution of psycholinguistics to the methodology of teaching FL is reduced to the following provisions: teaching a language involves the development of speech activity; since in teaching foreign languages its communicative function is of particular importance, therefore, the situational nature of speech and the presence of relevant situations are taken into account; the exercises should be a task, the solution of which develops the skills of the student, at the same time activating his mental activity; in order for speech activity to interest students, motivation is needed. The methodology of teaching foreign languages is not limited to the connection with the specified basic sciences, but uses the knowledge and methods of other, socalled related sciences. The general outlines of the learning process can be presented in terms of cybernetics - a science, the subject of which is control processes occurring in complex dynamic systems.

Cybernetic analysis of pedagogical phenomena contributes to a clear isolation of the interrelated links and conditions of the pedagogical process, allows you to introduce elements of programmed teaching into teaching foreign languages. The programmed methods solve the problem of optimizing the management of the educational process. The use of statistical analysis methods contributes to the improvement of the scientific 
level of the methodology. The use of methods of mathematical statistics, mathematical linguistics, information theory allows us to solve the issues of rationalizing the process of teaching foreign languages. Reliance on basic and related sciences is the most important condition for raising the scientific level of the methodology. One of the important tasks of the theoretical methodology is the scientific synthesis of basic and related sciences in their dialectical unity and their use in a transformed form, taking into account the goals, stages, conditions of education.

The following problems were identified before the method:

- definition of a foreign language as an academic subject;

- study of the teacher's activities (development of forms, methods, teaching techniques);

- studying the student's activities (checking the effectiveness of the techniques used, studying the student's development);

- the establishment of specific patterns, the determination of the scope of the laws of sciences adjacent to the methodology and the identification of their specific refraction in the methodology.

It is obvious that the process of teaching foreign language speech is extremely multidimensional. Motivation in learning a foreign language is an internal driving force that makes a person spend time and energy on learning a foreign language. Foreign languages are becoming one of the main factors of both socio-economic and general cultural progress of society. Learning motivation can be divided into positive and negative. So, the construction "if I learn English, I will get excellent on the exam" is a positive motivation. However, the construction "if I learn English, I will pass the exam and I will not be expelled" is negative. Motivation can also be divided into external and internal. External motivation is not directly related to the content of the subject, but is due to external circumstances (being an excellent student in all subjects, the student tries to have "excellent" in a foreign language - an external positive motive; the student learns a foreign language because of the fear of strict parents or a teacher - an external negative motive ). Extrinsic motivation comes in two flavors: broad social motivation and narrow-minded. External motivation "the learning process is associated with a rather acutely felt sense of civic duty to the country, to dear, close people, associated with the idea of learning as a way to master the great values of culture, with the idea of learning as a way to fulfill its purpose in life."

The goals of teaching a foreign language are an important methodological category. The starting point in determining the strategic goal of education is the social order of society in relation to the younger generation. In particular, foreign language education throughout almost the entire twentieth century consisted of a high-quality mastery of the subject. Then there was a turn from grammar-translation methods to the problem of practical mastering of a foreign language. However, the very concept of "practical knowledge of a foreign language" was clarified and concretized depending on the level of development of the methodology and related objectives of teaching the subject was understood: - mastering speech within a certain framework;

- the formation of skills and abilities to understand the thoughts of other people and express their thoughts (in oral and written forms);

- development of speech skills in all types of speech activity;

- learning to communicate on the FL in the unity of all its functions: cognitive, regulatory, valueorientational, etiquette. Such dynamics in the development of the interpretation of the goal of teaching a foreign language reflects the essence of the development of the methodology as a science and related areas of scientific knowledge.

The study of foreign languages in modern society is becoming an integral part of the professional training of specialists of a wide variety of profiles 
and the successful solution of issues of professional growth and the expansion of contacts with foreign partners largely depend on the quality of their language training.

\section{LITERATURE:}

[1] Babansky Yu. K. Teaching methods in a modern comprehensive school. - M .: Education, 1985.

[2] Belyaev BV Psychological foundations of mastering the vocabulary of a foreign language. - M., 1964.

[3] Bim I.L. Methodology of teaching foreign languages as a science and problems of a school textbook. - M .: Russian language, 1977.

[4] Questions of methods of teaching foreign languages in secondary and higher schools / ed. A.S.Shklyaeva. - Kazan: Kazan State. University, 1961 .-- 263 p.

[5] Galskova N.D. Modern methods of teaching foreign languages: $\mathrm{M}$ : Glossa, Moscow, 2000.

[6] Gez N.I., Lyakhovitsky M.V., Mirolyubov A.A. and other Methods of teaching foreign languages in secondary school. M., 1982.

[7] Glukhov B.A., Shchukin A.N. Terms of teaching Russian as a foreign language. M .: russ.yaz., 1993. - p. 83.

[8] Gurvich PB, Kudryashov Yu. A. Lexical skills that determine speaking in a foreign language // General method of teaching foreign languages. Reader. - M., 1991. 